\title{
Biologically Inspired Micro-Flight Research
}

\author{
David L. Raney and Martin R. Waszak \\ NASA Langley Research Center \\ Hampton, VA 23681
}

\begin{abstract}
Natural fliers demonstrate a diverse array of flight capabilities, many of which are poorly understood. NASA has established a research project to explore and exploit flight technologies inspired by biological systems. One part of this project focuses on dynamic modeling and control of micro aerial vehicles that incorporate flexible wing structures inspired by natural fliers such as insects, hummingbirds and bats. With a vast number of potential civil and military applications, micro aerial vehicles represent an emerging sector of the aerospace market. This paper describes an ongoing research activity in which mechanization and control concepts for biologically inspired micro aerial vehicles are being explored. Research activities focusing on a flexible fixedwing micro aerial vehicle design and a flapping-based micro aerial vehicle concept are presented.
\end{abstract}

\section{INTRODUCTION}

Nature provides numerous examples of efficient sustained controlled agile flight. In many cases differences between the requirements for animal flight and engineered flight systems are substantial but there remains significant potential to study nature and apply the lessons learned to solve challenging problems involving flight. Biological inspiration applied to aeronautics is certainly not new. Stephen Dalton notes in his book: "When Wilbur and Orville were studying the principles of flight, they had frequently returned to the birds to check their theories." [1] Of course, scaling differences between biological systems and engineered systems require careful consideration. However, in the case of very small flight vehicles, animal flight serves as an excellent basis for motivation, innovation, and comparison.

This paper describes research being conducted at NASA Langley Research Center and under NASA sponsorship as part of the NASA Morphing Project. ${ }^{[2]}$ The Morphing Project is part of the Breakthrough Vehicle Technologies Project, Vehicle Systems Program and supports fundamental research in smart materials, adaptive structures, micro flow control, optimization, and controls. ${ }^{[3]}$ The objectives of the project are to develop and assess advanced technologies and integrated component concepts to enable efficient, multi-point adaptability in flight vehicles. The biologically inspired research activities seek to apply knowledge and lessons learned from the biological sciences to enable radical improvements in the integrated aerodynamic, structural, and control characteristics of aircraft. ${ }^{[4]}$

Biologically inspired flight research seeks to explore and exploit flight technologies inspired by biological systems (insects, birds, bats, etc.) to enable new capabilities including miniaturized flight systems and components, intelligent autonomy and collaborative groups, bird-like agility, and exploiting atmospheric effects. Ongoing activities include the study of aeroelastic fixed wing micro aerial vehicles, resonance-based flapping flight, dynamic soaring, bio-inspired wing concepts, muscle-like actuation, and collaborative control. This paper will describe recent results from the efforts to characterize the dynamics and control properties of an elastic membrane wing micro aerial vehicle and explore the potential to achieve highly agile flight by exploiting resonance-based flapping flight.

Before proceeding to the specific research results a brief definition of the micro aerial vehicle (MAV) class will be presented and the potential value of MAVs will be discussed. Micro aerial vehicles are generally considered to have a maximum dimension less than 6 inches, a mass of less than 0.1 pounds, and to fly at Reynolds numbers of less than $10^{4}$. DARPA originally sought to develop micro aerial vehicles as rapidly deployable reconnaissance platforms for use by military units on the battlefield where access is limited and stealth is important. However, MAVs clearly offer the potential to fulfill numerous other military and civil applications including inspection of difficult-to-access structures, search and rescue, delivery of micro payloads, communications relay, and remote/distributed sensing. Market sectors that could benefit from these uses include public safety organizations (e.g., police and fire departments); news and entertainment production; agriculture, forestry, environmental and wildlife management agencies; meteorological and atmospheric scientists, and many others. 
The development of MAVs has benefited from the support of government funding (e.g., DARPA's MAV Program). MAVs have also benefited from efforts to develop miniaturized low power components for application in consumer electronic and telecommunication products. However, the full potential of MAVs has not yet been realized due to a lack of understanding of low Reynolds number and unsteady aerodynamics, the lack of experimental data, and the lack of miniature high precision low power sensors, actuators, and computational units. MAV designers have generally relied on the inherent stability for their airframes. Existing MAVs also lack the level of agility required for many applications. The efforts at NASA are intended to address these technical barriers and support the further development of MAVs and other vehicles.

\section{AEROELASTIC FIXED WING MAV}

Micro aerial vehicles (MAVs) represent a potentially inexpensive and expendable platform for surveillance and data collection in situations where larger vehicles are not practical. Many potential uses of MAVs will require autonomous cooperative and collaborative control capabilities so that large numbers of MAVs can be used to cover a large operational area. An aeroelastic membrane wing MAV has been developed with the ability to adapt to atmospheric disturbances via a passive adaptive washout mechanism. This vehicle has been the subject of research to develop an understanding of its flight dynamics and a capability to develop, implement, and test autonomous and collaborative control schemes. ${ }^{[5,6]}$

\section{FLEXIBLE WING CONCEPT}

An MAV that utilizes a flexible wing concept was developed by researchers at the University of Florida. ${ }^{[1]}$ The flexible wing utilizes a combination of biologically inspired design and the incorporation of modern composite materials. The wing is thin and undercambered as are those of small birds and bats. The vehicle is constructed with a carbon fiber skeleton and the wing is covered with a thin latex rubber membrane (see Figure 1).

The flexible nature of the wing can provide several advantages over its conventional rigid counterpart. The wings have the ability to adapt to the airflow in a fashion that is thought to provide smoother flight in gusty conditions. This is accomplished via a passive mechanism that is referred to as adaptive washout. In sailing vessels adaptive washout is produced through twist of the sail in response to gusts or velocity changes. This property greatly extends the wind range of the sail and produces more constant thrust (lift), even in gusty wind conditions.

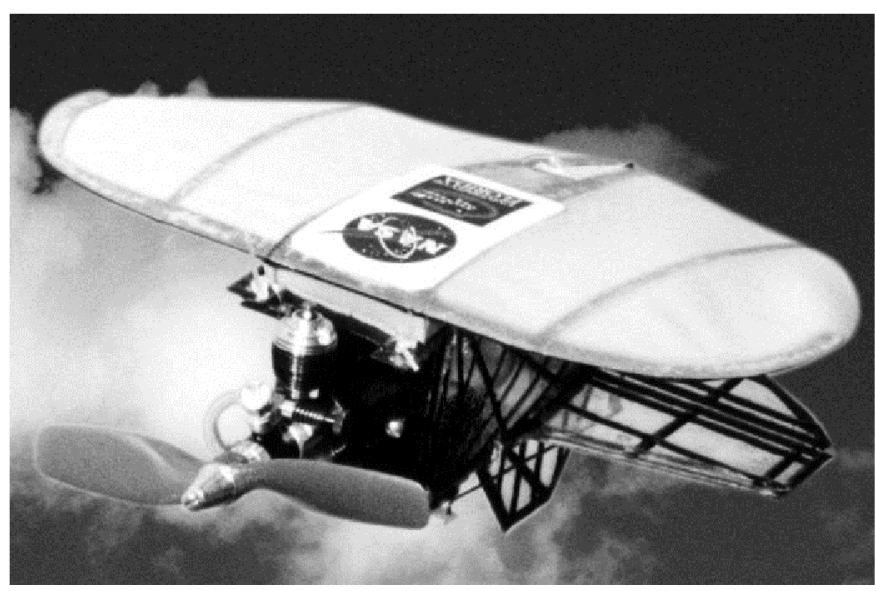

Figure 1 - photograph of Univ. of Florida MAV.

Similarly, the shape of the MAV wing changes as a function of airspeed and angle of attack. Adaptive washout is produced by membrane extension and twist of the wing structure, resulting in angle of attack changes as well as decambering along the length of the wing. For example, as the plane hits a head-on wind gust the airspeed suddenly increases. The increased airspeed causes a shape change in the wing that decreases the lifting efficiency, but because the airspeed in the gust is higher, the wing maintains nearly the same lift. Once the airspeed decreases, the wing recovers to the original configuration. If there is a decrease in the relative airspeed, the angle of attack increases and the wing becomes more efficient and near constant lift is restored. The net result is a wing that is thought to fly more smoothly in gusty conditions than its rigid counterparts. Hundreds of wing configurations have been built and flown, and the more flexible wings generally exhibit better flying qualities in terms of the precision with which the vehicle can be flown and its sensitivity to wind gusts (though this assertion is only based on subjective pilot assessment).

\section{VEHICLE DESCRIPTION}

The University of Florida MAV (UFMAV) used in this investigation incorporates a high mounted flexible membrane wing and low mounted cruciform tail attached to a tapered fuselage with rectangular cross section (see figure 1). The thin cambered wing structure is constructed of unidirectional carbon fiber laminate forming a leading edge spar and chordwise ribs (or battens). A 4 mil thick flexible latex membrane material is bonded to the spar and batten. The fuselage is a trusslike design constructed of a carbon fiber/epoxy material covered with a thin transparent monofilm membrane. A more detailed description of the vehicle and its construction can be found in reference 8 . Table 1 summarizes the pertinent geometric and mass properties of the vehicle. Off the shelf components (motor, servos, receiver, batteries, cameras, etc.) were used for the 
Table 1 - UFMAV geometric and mass properties.

\begin{tabular}{|c|c|}
\hline Empty Weight & $0.12 \mathrm{lbs}$ \\
\hline Wing Area & $19.8 \mathrm{in}^{2}$ \\
\hline Span & 6 in \\
\hline Mean Chord & $3.3 \mathrm{in}$ \\
\hline $\begin{array}{l}\text { Moments of Inertia: } \\
\qquad \begin{array}{l}\text { Ixx } \\
\text { Iyy } \\
\text { Izz } \\
\text { Ixz }\end{array}\end{array}$ & $\begin{array}{l}0.086{\mathrm{lb}-i \mathrm{in}^{2}}^{2} \\
0.23 \mathrm{lb}-\mathrm{in}^{2} \\
0.21 \mathrm{lb}-\mathrm{in}^{2} \\
0.037 \mathrm{lb}-\mathrm{in}^{2}\end{array}$ \\
\hline
\end{tabular}

vehicle systems to minimize cost. The vehicle has an empty weight of approximately 55 grams, a useful payload of approximately 20 grams, and flies at airspeeds between 10 and $30 \mathrm{mph}$.

The maximum dimension (including length and wing span) of the vehicle is six inches. The camber of the unloaded wing is approximately 6.5 percent of the root chord with the maximum camber occurring at approximately 30 percent chord and is uniform across the span. The wing is mounted at an incidence (the angle between the root chord line and the longitudinal axis of the fuselage) of approximately nine degrees.

Control is accomplished using two independently controlled elevons that are actuated symmetrically and antisymmetrically using small rotary servos. A small gas engine normally provides propulsion with a three-inch diameter propeller with a pitch of 1.25 . However, an electric motor was used during wind tunnel tests to more accurately control propeller $\mathrm{rpm}$ and is used in the simulation model as well.

The vehicle used for the study described here represents the University of Florida design as it existed almost three years ago. The design has continued to be refined and now has much better flight characteristics and performance, $;^{[7]}$ in part as a result of the research described herein.

\section{QUASI-STATIC ELASTIC AERODYNAMICS}

The benefits of the flexible membrane wing appear substantial. However, the nature of MAVs in general, and the flexible wing concept in particular, make analysis and design of the vehicle quite challenging. Despite this fact, the vehicle provides an excellent basis upon which to develop and apply ongoing research in dynamics and control, aeroservoelasticity, multi-functional structures, mircoelectronics, measurement and actuation systems, and many others. NASA has been collaborating with the University of Florida to develop an understanding of the underlying physical phenomena associated with the vehicle concept with a goal of enhancing the vehicle design and developing a capability for investigating autonomous and collaborative control technologies. ${ }^{[6,7,8]}$

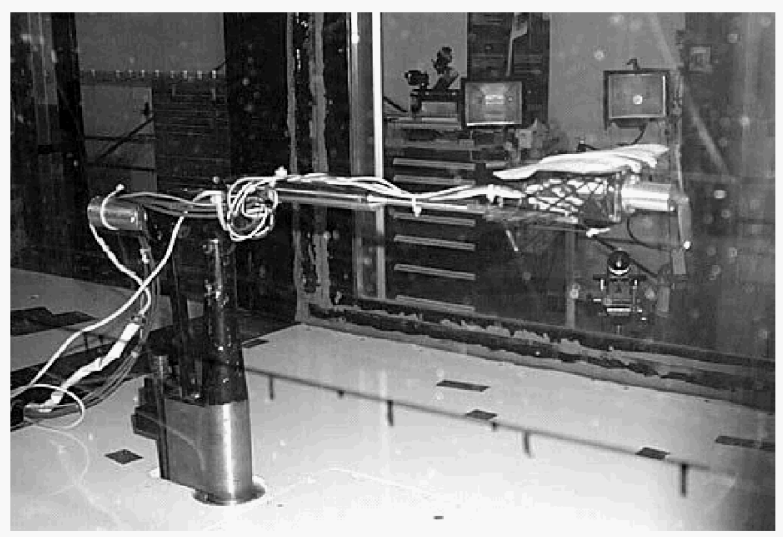

Figure 2 - UFMAV mounted in BART.

Wind tunnel tests were performed to provide data with which to investigate the benefits of the aeroelastic wing concept and to support related research. ${ }^{[5]}$ The results also provide a basis for the dynamic simulation model and control system design described later in this paper. ${ }^{[6]}$

The wind tunnel tests were conducted in the Basic Aerodynamics Research Tunnel (BART) at NASA Langley Research Center. ${ }^{[10]}$ The purpose of the tests was to collect a variety of data to aid in the study of the dynamics and control properties of the UFMAV concept. The data consist of aerodynamic forces and moments measured with an external 6-component strain gauge balance, static wing deformation data from a projection moiré interferometry (PMI) system, ${ }^{[1]}$ dynamic wing deformation data from a high speed videogrammetry system, ${ }^{[12]}$ and digital video of flow visualization using smoke and helium bubbles. Figure 2 depicts the UFMAV mounted in BART.

The data were collected at three dynamic pressures (1.0, 1,6 , and $2.0 \mathrm{psf}$ ), two power settings (power off and trim power), and a range of angles of attack, sideslip angle and control surface positions for a rigid wing and three different batten/membrane arrangements. The onebatten design exhibits more flexibility and larger membrane stretch. The two-batten design is, by comparison, stiffer and exhibits less membrane stretch under aerodynamic load. Both wings were tested using a 4 mil latex membrane. A six-batten wing was covered with an inextensible monofilm membrane that further increased the stiffness of the wing and exhibited less membrane deformation and vibration. The rigid wing was constructed of a two-batten frame covered with a graphite sheet.

Aerodynamic performance of each wing characterized by $L / D$ at a power off condition is summarized in figure 3 . The maximum L/D of approximately 3.0 is relatively independent of wing configuration. It is interesting to note that a comparable rigid fixed wing micro aerial vehicle, Aerovironment's Black Widow, has twice the maximum L/D of the vehicle described herein. ${ }^{[13]}$ An alternate fuselage configuration was assessed to determine the effect of streamlining on vehicle L/D. The 


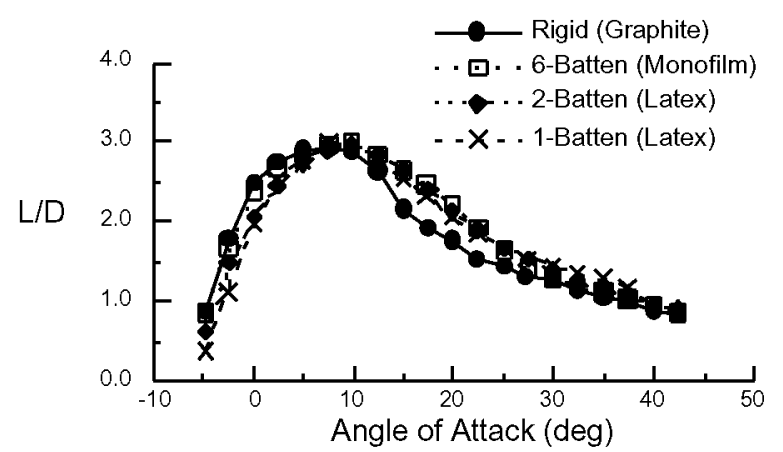

Figure $3-L / D$ for various wing configurations, ( $q=1.6 \mathrm{psf}$, prop pinned).

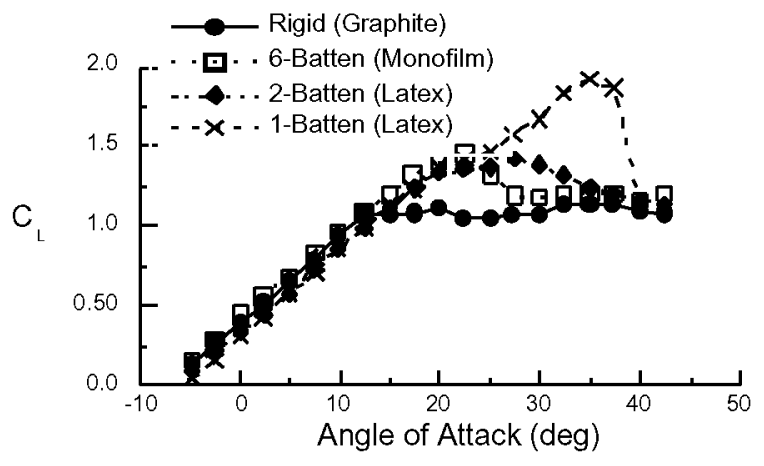

Figure 4 - lift coefficient vs. angle of attack for configurations with varying wing stiffness (power off).

baseline fuselage and a streamlined fuselage had the same wing installed at the same incidence angle. The streamlined configuration had a 20 percent greater maximum L/D than the baseline configuration. All subsequent UFMAV designs have used streamlined fuselages.

Figure 4 depicts the lift curves for the various wing configurations. For small angles of attack all the wings demonstrate similar lift characteristics. However, it is clear that the membrane wings stall at much higher angles of attack than the rigid wing. In fact, the most flexible wing configuration has double the stall angle of the rigid wing configuration (35 degrees and 15 degrees, respectively, for the power off case). This could be a key factor in enhancing the range of operation and agility of micro aerial vehicles.

These results are similar to the results for other low aspect ratio, low Reynolds number wings presented in reference 14, but there are important differences. At low angles of attack the aeroelastic wings behave like rigid wings with similar aspect ratio. The lift curve slope for the UFMAV is approximately 2.9 with power off. The lift curve slopes of similar rigid wings described in Reference 14 at comparable Reynolds number and aspect ratio ( $R e=70,000, A R=2)$ are approximately 2.9 as well. However, these wings have stall angles between 12 and 15 degrees. The stall angles of the aeroelastic wings are between 30 and 45 degrees (i.e., stall angle of the vehicle plus the wing incidence angle) and are similar to
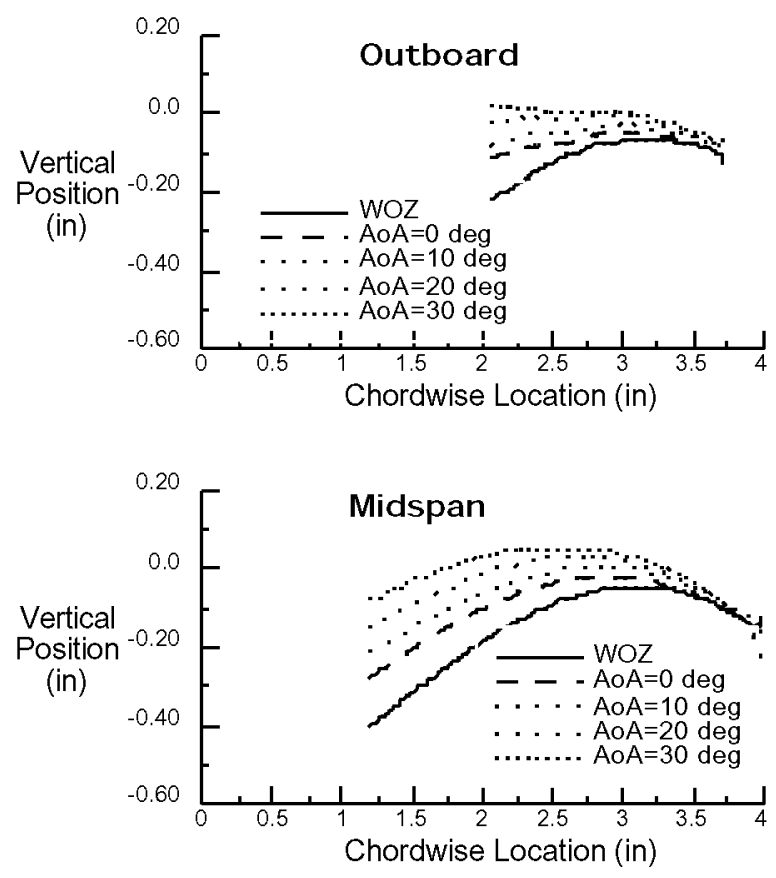

Figure 5 - wing camber of two-battened latex configuration for range of angles of attack ( $q=1.6 \mathrm{psf}$, trim power).

that of much lower aspect ratio rigid wings ( $A R=0.5$ to 1.0). However, the very low aspect wings exhibit lower lift curve slopes of 1.3 to 1.7. The aeroelastic UFMAV wings appear to exhibit the stall behavior similar to rigid aspect ratio 0.5 to 1.0 wings and the lift generating capability of rigid aspect ratio 2.0 wings.

Understanding how this is accomplished requires determining how the wing responds to changes in the flow conditions. Two methods were used to measure the structural deformation of the wing under various loading condition: PMl and videogrammetry. Both of these methods have the virtue that they do not require direct contact with the vehicle. This is especially important for the small highly flexible wing of the UFMAV where it is difficult, if not impossible, to use typical sensors (e.g. accelerometers, strain gauges) without altering the behavior of the wing.

Figure 5 depicts the mean chordwise deformation of the wing at two spanwise locations, midspan and outboard. The results shown are for the two-batten latex configuration. The wing leading edge is near a chordwise locaton of 4 inches. The chordwise deformation is presented relative to the wing at $q=0$ psf, i.e., wind-off zero (WOZ). The deformation data is determined at $\mathrm{q}=1.6 \mathrm{psf}$ and trim power setting at four angles of attack: $0,10,20$, and 30 degrees.

It is clear from these plots that the wing undergoes significant deformation. The maximum displacement of the membrane is approximately 0.25 inches at 30 degrees of vehicle incidence. The effect is to gradually reduce the incidence and camber of the wing as angle of 
attack increases. The degree to which the camber is reduced increases with span. Thus, though the vehicle may be at 30 degrees incidence, the wing is subject to a much smaller local angle of attack.

\section{STABILITY AND CONTROL}

A simulation model was developed to assess the stability and control properties of the UFMAV and to serve as a basis for control system design studies. The equations of motion were coded using Matlab/Simulink. ${ }^{[15]}$ The simulation includes the longitudinal and lateral-directional equations of motion, models for thrust and the aerodynamic forces and moments, and a standard atmosphere model.

The aerodynamic and propulsion models were obtained primarily from wind tunnel data collected in BART. Linear regression analysis was used to generate functions that approximate the dependence of the forces and moments on angle of attack, sideslip angle, and propeller $\mathrm{rpm}$ for a region over which the aerodynamics are linear. This simplification limits the angle of attack to values below 20 degrees and sideslip to values between -5 and 5 degrees. Cross terms between angle of attack, control deflection, and motor rpm are used to account for the dependence on propeller slipstream effects and the effect angle of attack has on control effectiveness.

The simulation model of the UFMAV was used to perform a number of analyses to assess the stability and control properties of the vehicle. ${ }^{[6]}$ The simulation was linearized about level trim conditions to assess the dynamic stability of the vehicle. Tables 2 and 3 summarize the frequency and damping of the linearized longitudinal and lateral-directional modes. The short period mode is stable for all three dynamic pressures but lightly damped. Its frequency increases with increasing dynamic pressure but the damping is essentially constant. The damping of the phugoid mode varies significantly and is unstable at the higher dynamic pressure. The lateral-directional modes are stable and the dutch roll mode is lightly damped. This is qualitatively consistent with behavior of the vehicle in flight. Note that the spiral mode is relatively unaffected by changes in dynamic pressure but that the magnitudes of both the roll and dutch roll modes increase with increasing dynamic pressure.

A preliminary guidance/control system was developed to enable investigations of autonomous and collaborative control issues. ${ }^{[6]}$ The controller is composed of two main parts: an inner-loop measurement-based nonlinear dynamic inversion controller for control of angular rates and an outer-loop navigation command follower for control of wind-axis angles. The measurement-based nonlinear dynamic inversion approach uses acceleration measurements in lieu of a complete on-board vehicle model, this approach is less sensitive to model errors and can
Table 2 - longitudinal modes.

\begin{tabular}{|c|c|c|c|c|}
\hline $\begin{array}{c}\text { Dynamic } \\
\text { Pressure } \\
\text { (psf) }\end{array}$ & $\begin{array}{c}\text { Short Period Mode } \\
\text { ratio }\end{array}$ & $\begin{array}{c}\text { freq. } \\
\text { (rad/sec) }\end{array}$ & $\begin{array}{c}\text { Phugomid } \\
\text { ratio }\end{array}$ & $\begin{array}{c}\text { freq. } \\
\text { (rad/sec) }\end{array}$ \\
\hline 1.0 & 0.13 & 23.3 & 0.44 & 0.85 \\
\hline 1.6 & 0.12 & 30.2 & 0.35 & 0.65 \\
\hline 2.0 & 0.12 & 32.6 & -0.56 & 0.67 \\
\hline
\end{tabular}

Table 3 - lateral-directional modes.

\begin{tabular}{|c|c|c|c|c|}
\hline $\begin{array}{c}\text { Dynamic } \\
\text { Pressure } \\
(\mathrm{psf})\end{array}$ & $\begin{array}{c}\text { Spiral } \\
\text { Mode }\end{array}$ & $\begin{array}{c}\text { Roll } \\
\text { Mode }\end{array}$ & \multicolumn{2}{|c|}{ Dutch Roll Mode } \\
\cline { 2 - 5 } & eigenvalue & eigenvalue & $\begin{array}{c}\text { damping } \\
\text { ratio }\end{array}$ & $\begin{array}{c}\text { freq. } \\
\text { (rad/sec) }\end{array}$ \\
\hline 1.0 & -1.04 & -27.7 & 0.094 & 21.1 \\
\hline 1.6 & -1.04 & -37.3 & 0.065 & 24.2 \\
\hline 2.0 & -1.02 & -42.8 & 0.050 & 25.9 \\
\hline
\end{tabular}

adapt to vehicle failures and/or damage. ${ }^{[16]}$ The method was extended to accommodate application to systems with fewer controls than controlled variables as is the case for the UFMAV. The guidance loop was designed to allow the simulation model to be integrated into an existing multiple vehicle collaborative control framework ${ }^{[17,18]}$ Preliminary results indicate that this is a viable approach for control of MAV's and similar systems. However, the limited control power provided by the elevons and throttle of the UFMAV make tracking flight path commands somewhat less precise than is desired. Future efforts will focus on improvements to this approach, robustness analysis, and use of this method as part of a multiple vehicle collaborative control scheme.

\section{RESONANCE-BASED FLAPPING MAV}

Numerous civil and military applications for MAVs have been proposed, and far more have yet to be imagined. However, the potential applications of current fixed-wing designs are necessarily limited due to maneuver and flight mode constraints. The successful fixed-wing design described above relies on relatively conventional scaled-down flight control approaches, and it does not possess the flight agility and versatility that would enable missions such as rapid flight beneath a forest canopy or within the confines of a building. In order to perform missions requiring extreme agility, MAV designs of the future may exploit flapping flight. The ability to vary wingbeat kinematics to generate large control moments and to rapidly transition between flight modes is a hallmark of nature's most agile fliers.

Although a number of flapping designs have been developed and demonstrated in a limited fashion, the creation of a practical ornithoptic MAV remains an elusive goal. Mechanical design, efficient actuation, power systems and control pose significant challenges to the feasibility of an ornithoptic MAV concept. As a means of efficiently producing high-frequency flapping motions, many natural flyers exploit resonant excitation of an 
aeroelastically tailored structure: muscle tissue is used to excite a structure which exhibits a vibratory mode shape that generates propulsive lift. ${ }^{[19-21]}$ Several research endeavors have considered MAV concepts that would operate in a similar fashion. ${ }^{[22-24]}$ Related research activities span a broad range of disciplines including ornithology, entomology, structures, materials, unsteady fluid dynamics and control. An extensive review of biological and aeronautical literature relevant to flapping flight was provided by Shyy ${ }^{[25]}$, and a highly multidisciplinary conference on low Reynolds number fixed and flapping-wing flight was held at Notre Dame in 2000. ${ }^{[26]}$

Shown in figure 6 are a number of flapping MAV concepts including Aerovironment's Microbat, Vanderbilt's Elastodynamic Ornithoptic Robotic Insect, and UC Berkeley's Micromechanical Flying Insect. The Microbat was produced by Aerovironment in partnership with UCLA and Caltech under funding from DARPA. ${ }^{[27]}$ To create Microbat, the team drew upon advancements in microstructures, miniature electronics, unsteady fluid dynamic modeling and multidisciplinary design optimization. The vehicle was capable of brief radiocontrolled flights, and its limitations provided great insight in terms of necessary directions for follow-on research activities.

However, one of the keys to agility in flapping flight is the ability to vary the wingbeat kinematics. The Microbat lacked this degree of control, relying instead on a conventional tail and rudder arrangement to provide flight control functions. One of the goals of the current investigation was to explore a more biologically inspired design for a flapping wing apparatus that could afford some degree of control over the wingbeat kinematics.
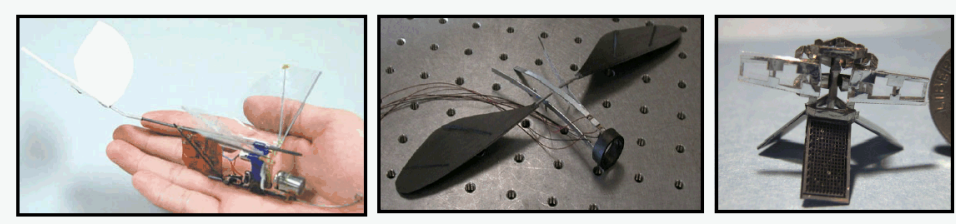

Figure 6 - (from left to right) Microbat,

Micromechanical Flapping Insect, and Elastodynamic Ornithoptic Robotic Insect

The Ornithoptic Robotic Insect is a concept for actuating the flapping wings of an elastodynamic ornithoptic device that was studied by Frampton and Goldfarb at Vanderbilt. ${ }^{[28]}$ The concept involved the mechanical amplification of small displacements produced by piezoceramic wafer actuators to excite vibrating wing structures. The investigators performed a parametric study of the impact of various combinations of bending and torsional wing stiffness on the thrust production of flapping wings.

Perhaps the most multidisciplinary effort to design an ornithoptic MAV is one that has been undertaken by the Micromechanical Flying Insect team at UC Berkeley. This team is responsible for an impressive series of biological and engineering studies aimed at understanding natural insect fliers in the size range of $2.5 \mathrm{~cm}$, and designing an artificial system capable of emulating that behavior ${ }^{[29.30]} \mathrm{A}$ key element of their research addresses the manner in which insects adjust the phasing between flapping and rotational motions of their vibrating wing structures for the purposes of flight control.

This section of the paper describes an ongoing research activity in which resonant flapping MAV concepts are being explored in a small project at NASA Langley Research Center. The study targets a size range of 15$20 \mathrm{~cm}$. The research does not seek to develop a flapping MAV design, nor prove the feasibility of such an ornithoptic system. ${ }^{\S}$ Rather, the goal is to develop insight regarding biologically inspired structural approaches, mechanical arrangements, actuation concepts, sensing, and wingbeat control approaches that could contribute to the body of knowledge required to create an agile MAV in which resonant excitation of an aeroelastically tailored wing structure is used to generate propulsive lift.

First, several insights and specifications are drawn from natural fliers in the MAV size range. The bat-like membrane wing structural concept from the University of Florida MAV is then adapted to create wings having size, weight and planform similar to that of a particular hummingbird example. Next, a biologically inspired arrangement of mechanical components is developed to provide control over vibratory wingbeat patterns, and results from a vibratory testbed apparatus able to generate wingbeat patterns that approximately match those exhibited by hummingbirds are presented. Finally, a feedback control circuit inspired by locust wing morphology is described that automatically tunes the actuation drive signal to the resonant flapping frequency.

\section{BIOLOGICAL INSPIRATION}

Although countless examples of highly successful flapping fliers exist in nature, perhaps the one that best demonstrates the characteristics we wish to possess in an agile MAV is the hummingbird. Hummingbird species bracket the size range of 6 inches and speed range of $25 \mathrm{mph}$, used to define MAV-class vehicles. Wing lengths range from about $33 \mathrm{~mm}(\sim 2.5$ " total span) for one of the smallest species (Calliphlox amethystina), to $135 \mathrm{~mm}$ ( 10.5" total span), for the Giant Andean (Patagona gigas). Wind tunnel tests have suggested maximum flight speeds for some species as high as 27 $\mathrm{mph}$, compared to 8 to $10 \mathrm{mph}$ for most fast-flying insects. $^{[32]}$

The agility, precision, and flight mode variability exhibited by hummingbirds is astonishing, and the creation of an

\footnotetext{
$\$$ Such proof clearly exists in the form of natural fliers. At issue, however, are the relative merits of rotary vs. flapping approaches to MAV flight. Spedding examines this topic. ${ }^{[31]}$
} 
artificial system that can perform similarly is a lofty goal. Precise control of body axis rotation and translation during hover feeding is a necessity for hummingbirds. Transition from hover to cruise may be affected in less than half a second, incurring accelerations of roughly 5 gs. Despite their relatively high power consumption during hovering flight, hummingbirds are able to cruise with considerable efficiency, and some species migrate across the Gulf of Mexico without feeding.

In terms of size, weight, and Reynolds number, hummingbirds occupy a niche between insects and larger birds, and their flight apparatus appears to represent a hybrid between the two approaches to flapping flight. Many insects employ a flight apparatus that relies upon resonant excitation of a relatively passive wing structure to produce a vibratory response that generates propulsive lift. Most birds, on the other hand, rely on highly articulated wing structures that move at the elbow and wrist as well as the shoulder joint. Their wingbeat kinematics are generally more complex, involving variation of the wing planform geometry throughout the flapping cycle. Although birds tend to flap their wings at the natural frequency of their biomechanical system, their highly articulated flapping motions cannot be fully described as the mere vibratory response of a passive structure. This additional degree of complexity would seem to endow birds with generally broader flight envelopes and greater variability of function in terms of flight modes and behaviors.

Although morphology of the hummingbird flight apparatus is distinctly avian, its mode of operation bears a strong resemblance to insects. Unlike all other birds, a hummingbird's wing joints are fused at the elbow and wrist, so the wing planform does not change during the flapping cycle. ${ }^{[32]}$ Flapping motions are actuated entirely from the shoulder joint, and wingbeat kinematics of the upstroke and downstroke are markedly similar. The wing exhibits a vibratory motion much like that of an insect wing: a non-articulated structure that is aeroelastically tailored to generate propulsive lift when excited at resonance. The relative simplicity of the hummingbird's flight apparatus and wingbeat patterns, together with its remarkable precision and flight mode variability, make it an attractive source of inspiration for mechanization and control concepts that may be applied to an agile ornithoptic MAV.

In order to use the hummingbird as a source of further insight, it makes sense to develop specifications that characterize those species in the size range of interest. A study by researchers at the University of Texas that investigated the load carrying capacity of several hummingbird species provides a useful starting point. ${ }^{[33]}$ Average characteristics for these species are presented in Table 3 from the study by Chai and Millard, which also provides an assessment of wing and flight muscle mass. Note the wingbeat frequencies ranging from $23.3 \mathrm{~Hz}$ to $51.7 \mathrm{~Hz}$. Approximate wingbeat frequencies for all hummingbird species range from $10 \mathrm{~Hz}$ (Patagona gigas) to $80 \mathrm{~Hz}$ (Calliphlox amethystina). ${ }^{[32]}$ Parameters $P_{p e r}$ and $P_{\text {zero }}$ in the table represent total mechanical power output of the flight muscle mass assuming perfect and zero elastic energy storage, respectively.

Two species that lie within the relevant size range are the Blue Throat (Lampornis clemenciae), and the Rivoli (Eugenes fulgens). These species are highlighted on the plot of wing length vs. total weight shown in Figure 7 for all hummingbird species. Also noted on this plot is Aerovironment's ornithoptic MAV design, the Microbat.

Table 3 - data for several hummingbird species. ${ }^{[33]}$

\begin{tabular}{|l|cccc|}
\hline & $\begin{array}{c}\text { Lampornis } \\
\text { clemenciae }\end{array}$ & $\begin{array}{c}\text { Eugenes } \\
\text { fulgens }\end{array}$ & $\begin{array}{c}\text { Archilochus } \\
\text { alexandri }\end{array}$ & $\begin{array}{c}\text { Selasphorus } \\
\text { rufus }\end{array}$ \\
\hline total mass, g & 8.4 & 7.4 & 3.0 & 3.3 \\
wing mass, g & 0.29 & 0.26 & 0.08 & 0.08 \\
flt muscle mass, g & 2.44 & 2.01 & 0.87 & 0.96 \\
wing AR & 8.2 & 8.4 & 7.1 & 7.4 \\
freq, Hz & 23.3 & 24.0 & 51.2 & 51.7 \\
length, mm & 85 & 79 & 47 & 42 \\
flap arc, deg & 151 & 150 & 126 & 163 \\
$\mathrm{U}_{\text {, }}$ m/s & 10.4 & 9.9 & 10.5 & 12.3 \\
$\mathrm{Re}^{\mathrm{C}}$ & 11400 & 9800 & 7400 & 7400 \\
$\mathrm{C}_{\mathrm{L}}$ & 1.46 & 1.67 & 1.42 & 1.41 \\
$\mathrm{P}_{\text {per }}$, Watt & 0.175 & 0.152 & 0.076 & 0.089 \\
$\mathrm{P}_{\text {zero }}$, Watt & 0.343 & 0.325 & 0.187 & 0.250 \\
$\quad f / 4$ & 6014 & 5653 & 6301 & 5528 \\
$\quad m / \beta / 2$ & 0.0107 & 0.0105 & 0.0093 & 0.0121 \\
\hline
\end{tabular}

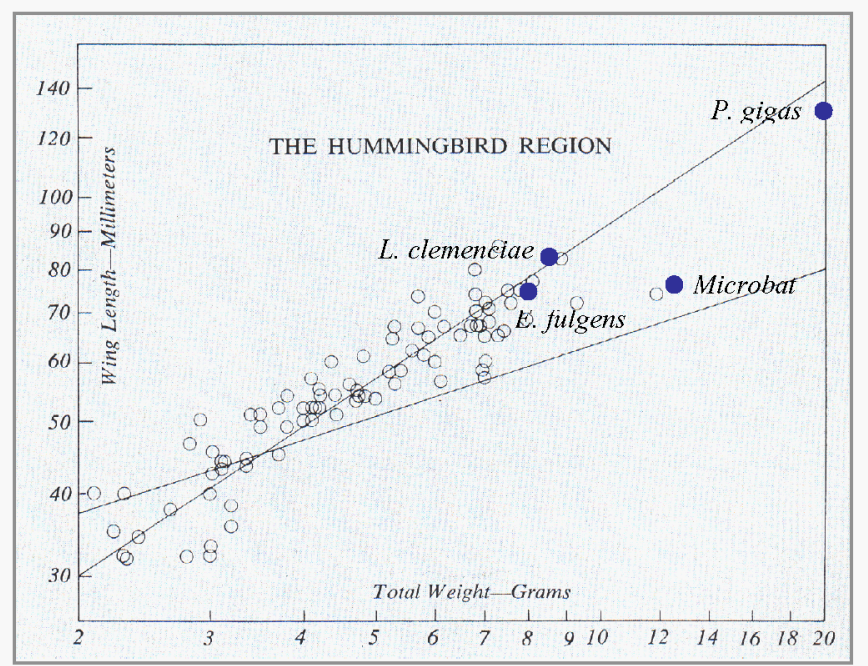

Figure 7 - plot of wing length vs. total weight for all hummingbird species. ${ }^{[32]}$

An empirical fit to the hummingbird data suggests that weight scales with wing length according to the relation shown in equation (1) ${ }^{[32]}$ Greenwalt also suggests that hummingbird wing length and flapping frequency scale according to equation (2).

$$
\begin{aligned}
& m \propto l^{3 / 2} \\
& f \propto l^{-5 / 4}
\end{aligned}
$$

Using values of mass, wing length, flapping frequency and flapping arc from Table 3 to compute average scale factors from these relations, it appears that a 
hummingbird-like MAV with wing length of $75 \mathrm{~mm}$ should flap its wings through a 150-degree flapping arc at approximately $25 \mathrm{~Hz}$ and weigh only 7.5 grams. The weight target for this conceptual vehicle represents an extreme challenge to the various subsystem technologies of structures, power systems, actuation, and miniaturized electronics. The realization of an artificial MAV with truly bird-like agility would seem to hinge upon the development of such ultra-lightweight components. However, it is not only the availability of suitable system components, but the particular arrangement and manner in which they are employed that will lead to a MAV with the desired capabilities. The following sections present concepts for mechanization and control of a vibrating wing apparatus that could provide lift, thrust, and maneuver moments for such a MAV if and when the necessary component technologies emerge.

\section{STRUCTURAL CONCEPT FOR FLEXIBLE WINGS}

To produce artificial wing structures with the desired flexible characteristics, a structural concept was adapted from the UFMAV design described previously. Although it employs a fixed-wing and propeller arrangement, this vehicle incorporates a very light flexible wing structure that is thought to provide improved stall margins and flying qualities. For the present investigation, this structural concept was applied to wing designs inspired by hummingbirds. Wing layouts were developed from photographs of hummingbirds with their wings extended that were scaled to have a wing length of $75 \mathrm{~mm}$. An example of a resulting composite wing structure is shown in Figure 8, along with the photograph from which it originated. The weight of the composite wing structure is 0.59 grams, compared to 0.26 grams for a natural wing of similar size from Table 3 .

Several features in the structure of the hummingbird wing appear important to capture in the artificial wing design. First, the quills of the primary flight feathers radiate from the shoulder region of the wing, rather than emanating from the leading-edge spar as in the University of Florida MAV. Radial orientation of structural wing members is a key element observed in natural fliers, and it has been found to greatly influence the flexible behavior of their wings. A thorough description of the crucial role that such orientation plays in the resulting torsional dynamics of insect wings is provided by Ennos. ${ }^{[34]}$ In the hummingbirds' case, the radial orientation of quills provides the flexible wing with reversible camber, enabling it to generate lift on both the downstroke and upstroke segments of the flapping cycle during hovering flight, in which the wing stroke plane is nearly horizontal. This reversible characteristic of the wing is highly developed in hummingbirds, as illustrated by the hovering specimen shown in Figure 9. ${ }^{[32]}$ Among avian species, hummingbirds possess proportionately the largest flight musculature associated with the upward portion of the flapping stroke. The reversibility of their flexible wing structure along with their unusual flight musculature is largely responsible for the hummingbird's prowess as a hovering flier.

Another critical feature that is required to generate the flexible behavior observed in Figure 9 is a wing surface that is capable of supporting compound curvature without puckering. The extensible compliant latex material used in the flexible wings of the University of Florida MAV has been shown in wind-tunnel tests to be capable of supporting such deformations. ${ }^{[5]}$
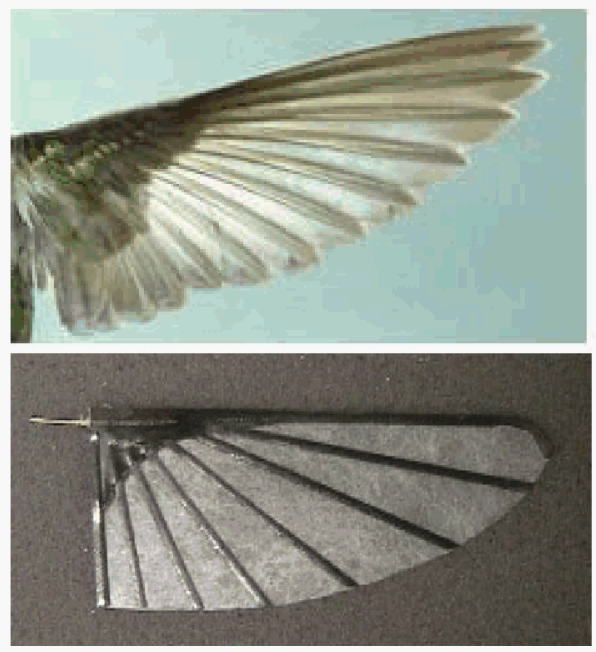

Figure 8 - extended humming-bird wing and a typical wing created by applying UF structural concept to hummingbird-inspired wing designs.

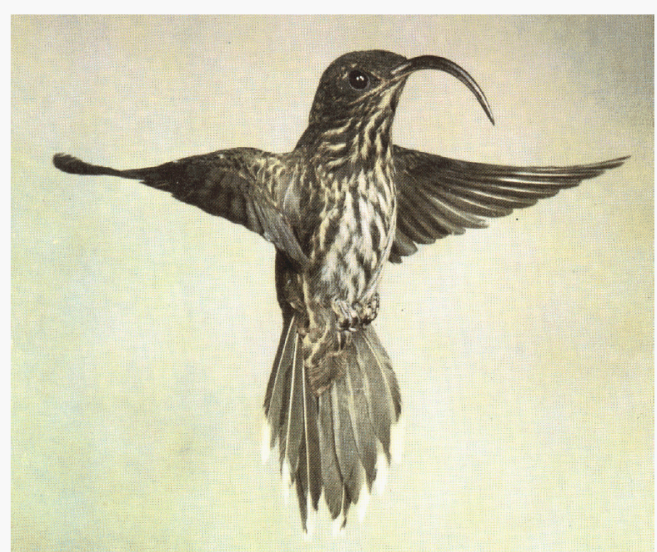

Figure 9 - A hummingbird in hovering flight illustrates the reversible camber exhibited by its flexible wing structure (Eutoxeres aquila). ${ }^{[32]}$

\section{GENERATION OF VIBRATORY FLAPPING MOTION}

If the motivation for pursuit of a flapping flight mechanism is bird-like agility, then a crucial goal is to provide some degree of control over the wingbeat kinematics as a means of changing flight modes or generating maneuvers. In order to achieve variability in wingbeat behavior, a vibratory flapping system was designed that includes a ball and socket joint at the shoulder. The design of the system represents an attempt to apply insights from the basic arrangement of skeletal and muscular components that drive a typical bird wing 
shown in Figure 10, which is drawn from Freethy, 1982. ${ }^{[35]}$ The storage of elastic energy has been found to be an important factor in the arrangement and operation of these components. We shall drastically simplify and then crudely model these components as an elastodynamic system, while attempting to retain the basic function of the arrangement. The simplified mechanical system shown in Figure 11 provides a basis for developing the model. The following paragraphs describe the various components, and the rationale for their arrangement.

In Figure 10, a ball-and-socket joint connects the coracoid to the humerus, constituting the shoulder of the bird. At point $h$ in Figure 11, this component is represented as a 3-degree of freedom ball-and-socket connection between a fixed rigid test stand and a rigid beam element having length $L_{1}$ and mass $m$, representing the humerus. The use of a rigid beam element in this capacity means that the flexible dynamics of the wing structure are neglected for the time being.

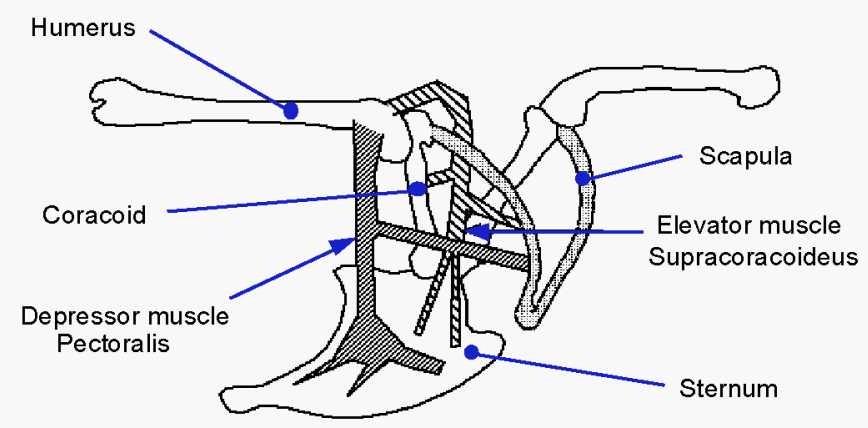

Figure 10 - basic arrangement of skeletal and muscular components comprising the avian flapping system. ${ }^{[35]}$

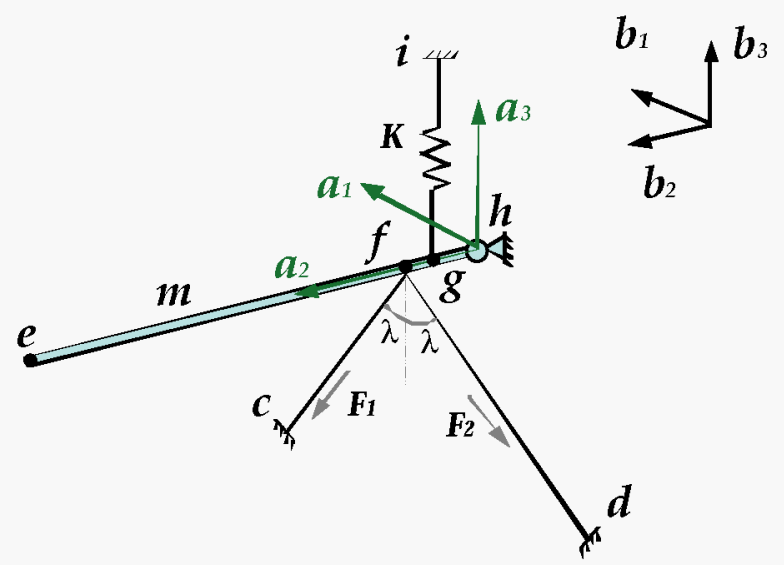

Figure 11 - Simplified arrangement of mechanical components used to approximate the natural system shown in Figure 10.

Two reference frames are defined consisting of bodyfixed axes $\{b\}$ and wing-fixed axes $\{a\}$, both having their origin at the shoulder joint, h, shown in Figure 11. Control over the relative amplitude and phasing of angular rates of rotation between these two coordinate systems enables the arrangement to generate changes in the vibratory wingbeat pattern. (The shoulder joint of insects is also designed to permit such control, but the insect's shoulder anatomy resembles a series of hinges that has been compared to the articulated rotor hub of a helicopter. ${ }^{[36]}$ It differs markedly from the ball-and-socket shoulder joint found in birds.)

Located distance $L_{2}$ from the shoulder joint $h$ in Figure 11 is the application point, $f$, for a pair of tendons that connect the beam representing the humerus to points $c$ and $d$, which represent the attachments of the depressor muscle pectralis to the sternum and scapula in Figure 10, respectively. The tendons are able to contract, thereby generating forces $F_{1}$ and $F_{2}$ that act upon the beam at point $f$. In Figure 10, the depressor pectoralis muscle serves to draw the wing down through a stroke plane having an inclination to the bird's body axis that may be varied by changing the relative magnitudes of muscular contraction that generate the sternumhumerus and scapula-humerus resultant forces. As a simplification in Figure 11, these tendons attach to the beam at equal and opposite angles to the $a_{2}-a_{3}$ plane with magnitude $\lambda$.

Located a distance $L_{3}$ from the shoulder joint is the attachment point, $g$, for a vertical spring that represents the elevator muscle, supracoracoideus, which raises the wing. The justification for representing this muscle with a single spring element is that the supracoracoideus passes through a small notch that permits it to travel around and over the top of the coracoid before reversing direction and attaching to the sternum, as shown in Figure 10. This notch constrains the line of action of the elevator muscle to pass through a point at the top of the coracoid, much as the force generated by the spring shown in Figure 11 acts through point $i$. The use of the spring element collectively represents the elastic storage potential that has been attributed to the sternum and scapula arrangement.

\section{VIBRATORY TESTBED APPARATUS}

A dynamic simulation model of the mechanical system shown in Figure 11 was programmed in Matlab ${ }^{\text {TM }} \cdot{ }^{[3]}$ The simulation indicated that the arrangement could provide control over vibratory wingbeat kinematics through variation of the relative amplitude and phasing of the forcing inputs $F_{1}$ and $F_{2}$. Based on these results, a vibratory flapping apparatus was constructed using the biologically inspired arrangement shown in Figure 11. The goal was to create a benchtop testbed capable of generating and controlling vibratory wingbeat patterns similar to those observed in hummingbirds. Dispensing with component weight limitations levied by the need for a flight-capable design led to the testbed shown in Figure 12. A crucial component of the apparatus is the 3-dof pinned ball-and-socket used for the shoulder joint. This joint permits a limited range of feathering and folding rotations, and unconstrained flapping rotation. The pinned ball-and-socket was resorted to after attempts 
with a true ball-and-socket repeatedly resulted in the ball departing from the socket when the system was excited at resonance. Nylon line connects the main spar of the wing, representing the humerus, to two electrodynamic linear actuators that provide input forces $F_{1}$ and $F_{2}$ representing the pectoralis. The supracoracoideus was represented by a spring that was attached to a point above the shoulder joint. The flexible wing structure, itself, consisted of the carbon and latex composite described previously.

Several experimental techniques have proven useful in assessing the performance of this apparatus. The first is the use of a tunable strobe light, which permits the creation of an aliased slow-motion video image of the high frequency wing vibrations. The use of the strobe greatly improves the ability to qualitatively assess the behavior of the flexible wing structure. Another effective technique is the placement of small LED devices at the tips of the wings to trace out the entire wingtip trajectory in a single photographic image. By combining these methods, it is possible to generate images that illustrate the large-amplitude vibratory flapping motion of the wings at resonance, as shown in Figure 13.

Control inputs to the apparatus consist of scale factors on the relative amplitude, phasing and waveform of commands to the two electrodynamic actuators. These provide a degree of control over the wingbeat pattern, enabling the system to approximate those exhibited by hummingbirds in various flight modes. The experimental techniques described above were useful in determining the input settings required to generate the desired wingtip trajectories. A comparison of wingtip trajectories produced by the testbed with hummingbird wingtip trajectories documented by Greenwalt is shown in Figure 14. The factors that are approximately matched in these figures include the stroke plane inclination to the body axis of the bird (or testbed), amplitude of the flapping arc, approximate geometry of the wingtip trajectory, and sense of rotation about that trajectory. Note that in forward flight, the wingtip travels in a clockwise sense about the trajectories shown in Figure 14 , while in reverse flight the sense is counter-clockwise. Transition between wingbeat patterns has been accomplished in as little as four flapping cycles $(0.16$ seconds.) These results suggest that the biologically inspired arrangement in Figure 11 provides sufficient control over the vibratory wingbeat pattern to enable the flight mode variability that would be required by an agile ornithoptic MAV.

The apparatus provides control over the wingtip trajectory as defined by a particular combination of folding and flapping motions. However, the feathering component of the vibratory wing motion produced by the testbed is uncontrolled. Many insects use the phasing between feathering and flapping motions as a steering mechanism, implying some degree of control over feathering rotations via moments generated at the

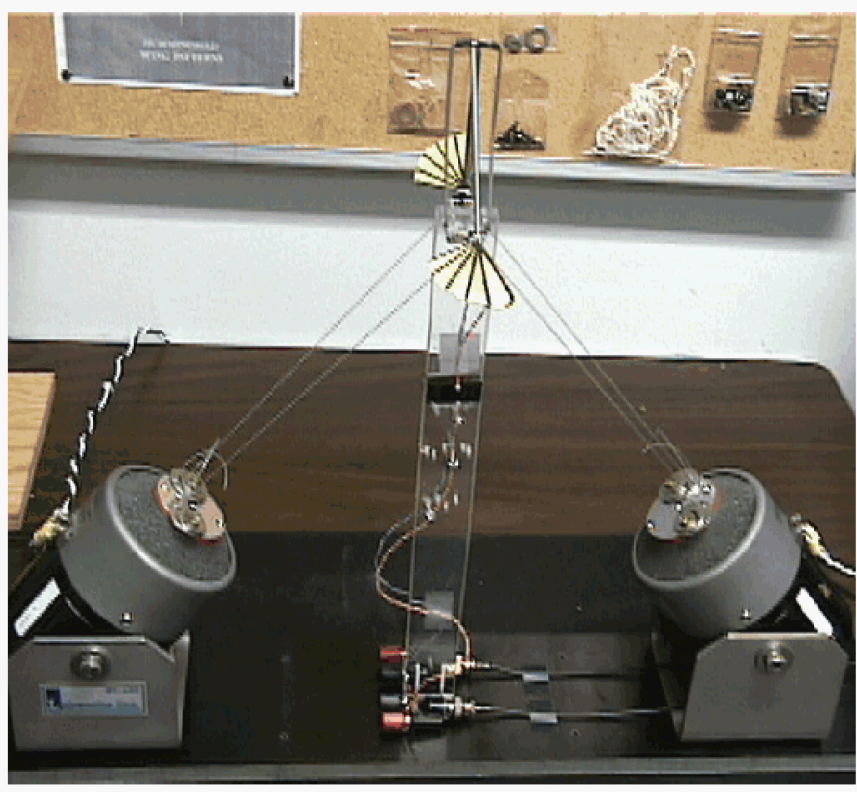

Figure 12 - shaker-actuated testbed designed to provide control of vibratory wingbeat patterns.

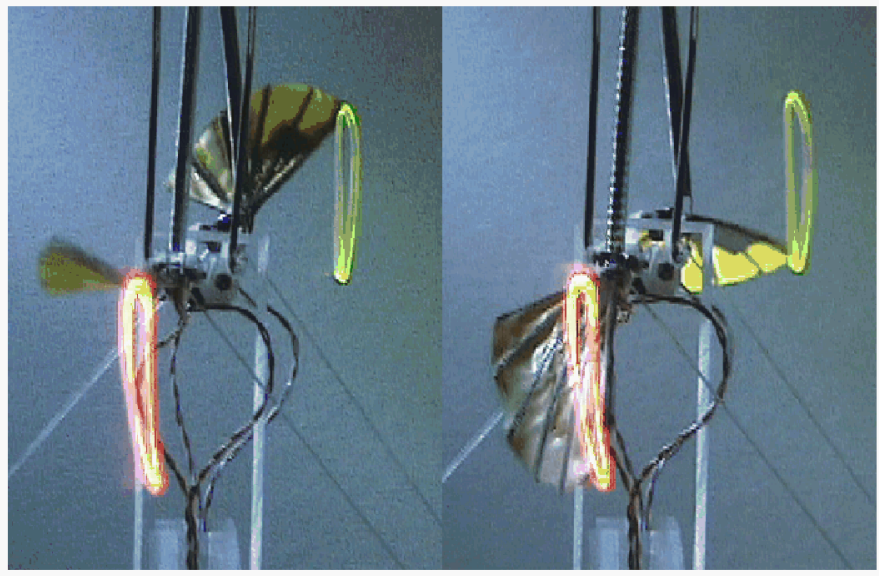

Figure 13 - strobed photographic images illustrating vibratory flapping motion and wingtip trajectories traced out by LEDs at resonant wingbeat frequency $(\sim 25 \mathrm{~Hz})$.
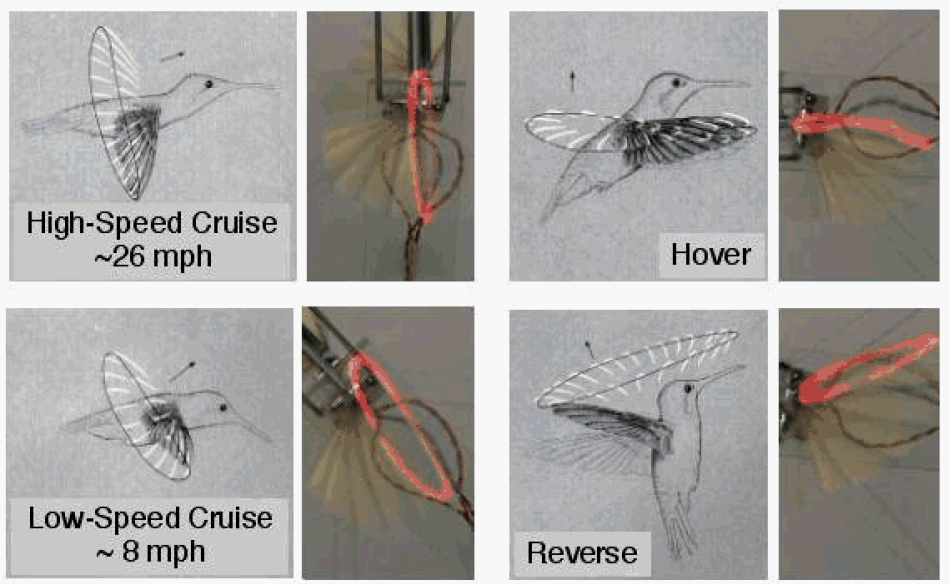

Figure 14 - comparison of wingtip trajectories produced by the vibratory flapping testbed with those exhibited by hummingbirds in various flight modes. ${ }^{[32]}$ 
shoulder joint. ${ }^{[29]}$ However, researchers have also found that insects rely heavily upon inertial and aerodynamic loading to affect rotation of the wing (Ennos). ${ }^{[38]}$ The degree to which hummingbirds exercise direct actuation and control of wing feathering rotations for steering purposes is uncertain. Although the feathering rotation is not directly actuated or controlled in the current mechanical arrangement, some degree of control may be achieved by introducing offsets between various tendon attachment points at the humerus in Figure11. This is a topic for further research.

It is important to distinguish between wing torsion and feathering motions. The former refers to structural deformation of the wing about the torsional axis, while the later is the rigid-body component of wing rotation about the $a_{2}$ axis. A similar distinction exists for bending and flapping components of wing motion. It is clear from Figure 13 that the experimental wing undergoes considerable bending and torsion at resonance. This behavior is strongly influenced by the stiffness distribution of the wing lay-up (dictated by ply number, membrane thickness, and dimensions of composite members.) Ideally, a prescribed mode shape, consisting of a particular combination of wing bending and torsion that has been tuned to generate propulsion and lift, would be designed into the wing structure at the desired resonant frequency by appropriately tailoring the composite lay-up. Aeroelastic tailoring of the wing structure is another topic for further research.

\section{CONCEPT FOR RESONANT TUNING}

A means of sensing the flexible behavior of the vibrating wing structure was found in the form of thin film piezoelectric strain rate sensors made of polyvinylidene fluoride ( $p v d f)$. These commercially available sensors, manufactured by Measurement Systems, Inc. (MSI), employ the piezo effect to produce a voltage output in response to strain rate. The thinnest devices available consist of a $28 \mu \mathrm{m} \times 15 \mathrm{~mm} \times 40 \mathrm{~mm}$ layer of "metalized" pvdf material. These sensors are easily bonded to the composite wing structure using a thin coat of spray adhesive, as shown in Figure 15. In this arrangement the sensor responds to a broad range of deformations, including the overall bending and twisting motions of the wing as well as individual batten and membrane vibrations. The voltage output of the sensor was found to be easy to use and quite repeatable. Sensors were applied to both wings of the testbed apparatus.

An RMS sensor output signal may be computed to provide a gross indication of the amplitude of vibration the flexible wing experiences at a given excitation frequency. It is then possible to experimentally ascertain the fundamental resonant flapping frequency of the wing structure by conducting an input frequency sweep and plotting RMS sensor output against input frequency. Such a plot is shown in Figure 16 for a flexible wing structure that resonates at approximately $24 \mathrm{~Hz}$.
The frequency response plot suggests the potential for a feedback control circuit that would automatically tune the actuator input frequency to the resonant frequency. The inspiration for such a tuning circuit derives from a recent text on the biomechanics of insect flight by Dudley. ${ }^{[18]}$ Dudley notes that certain dome-shaped sensory organs (campaniform sensillae) identified within the structure of locust wings have been found to respond specifically to wing deformation. These organs tend to be concentrated near the base of the wings, where bending is greatest. Feedback signals from these "stretch receptors" are used to drive the primary flight musculature within in the locust's body. Such feedback directly stimulates and phase-locks thoracic motor neurons at the wing oscillation frequency. In fact, the vibratory motion of the wing itself is both necessary and sufficient to generate the neural stimulus to the muscle tissue that sustains the oscillation. Hence, the biomechanical vibratory system simply contains neuromuscular feedbacks from the flexible wing structure that cause it to operate at resonance when activated.

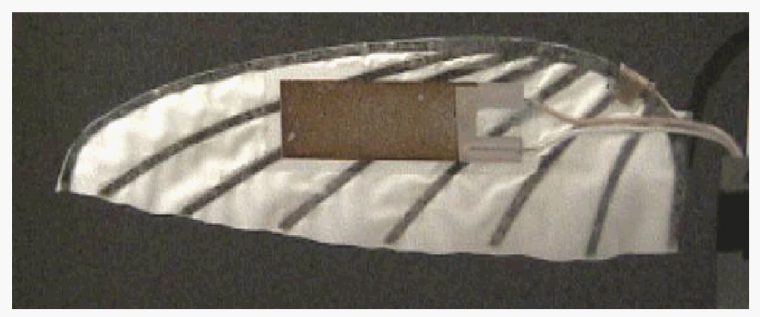

Figure 15 - thin film pvdf strain-rate sensor device bonded to flexible wing structure.

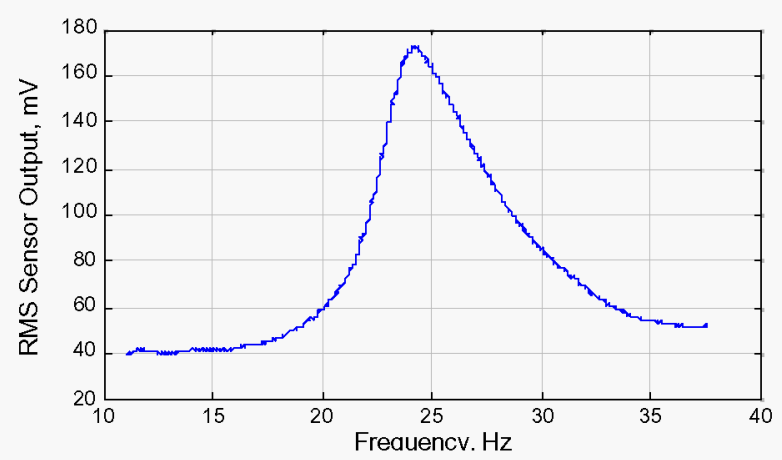

Figure 16 - plot of the RMS strain-rate sensor output vs. input frequency showing resonant peak at $24 \mathrm{~Hz}$.

It is possible to devise a feedback circuit that employs the thin film strain rate sensor in a capacity similar to that of the locust's campaniform sensillae. The simplicity of deriving such a circuit becomes obvious upon consideration of the forced response of a $2^{\text {nd }}$ order system with positive rate feedback:

$$
\ddot{\eta}+2 \zeta \omega_{n} \dot{\eta}+\omega_{n}^{2} \eta=F
$$

let $F=G \dot{\eta}$

$$
\ddot{\boldsymbol{\eta}}+\left(2 \xi \boldsymbol{\omega}_{n}-G\right) \dot{\boldsymbol{\eta}}+\boldsymbol{\omega}_{n}^{2} \boldsymbol{\eta}=0
$$


Let $\eta$ represent the generalized modal coordinate for the first bending mode shape of the wing, and the rate signal, $\dot{\eta}$, represent output of the strain rate sensor (an idealization which assumes that the sensor responds only to the first bending mode of the structure). Let input, $F$, represent a generalized force input to the wing structure that is generated by a command to the electrodynamic actuators under the condition $F_{1}=F_{2}$. Setting the forcing function equal to feedback gain, $G$, times the strain rate sensor output, $\dot{\eta}$, yields the relation shown in equation 5 . The linear system is dynamically unstable for sufficiently high feedback gain, $G>2 \zeta \omega_{n}$, resulting in a divergent oscillation of the vibrating structure. However, insertion of a saturation nonlinearity on the strain-rate feedback signal prior to multiplying by gain $G$, causes the system to exhibit a limit-cycle oscillation at the resonant frequency of the $2^{\text {nd }}$ order system, rather than a divergence. The saturation represents a limit on the power used to drive actuators, preventing the force input from increasing without bound. The amplitude of the limit cycle may be controlled by varying $G$, which is equivalent to scaling the power used to drive the actuators. Increasing $G$ results in greater flapping amplitude, generating greater propulsive lift while maintaining the same flapping frequency - a convenient throttle control for the resonant flapping system.

\section{CONCLUSION}

This work has contributed to an emerging body of multidisciplinary knowledge in the area of biologically inspired micro-scale flight. The research activity seeks to gain and apply an understanding of natural fliers in the size range of the micro aerial vehicle class. An aeroelastic fixed wing micro aerial vehicle (MAV) concept from the University of Florida has been investigated to determine the degree to which its bat-like membrane wing enhances vehicle performance. Wind tunnel testing was performed to identify the aerodynamic properties of the vehicle and the effects of the membrane wing.

The results indicate that the elastic membrane wing allows the vehicle to achieve higher angles of attack without stalling. This fact coincides with significant static deformation of the wing under load, particularly at higher angles of attack. It appears that the deformation allows the wing to experience a smaller effective angle of attack at high vehicle attitudes. A dynamic simulation model of the aeroelastic fixed wing MAV has been produced for flight control studies and a preliminary flight control system has been designed.

A related research activity has been undertaken to design and control a vibratory flapping wing apparatus using insights provided by bird, insect, and bat morphologies. Results were presented from a benchtop testbed used to explore a vibratory system that embodied such insights. The bat-like membrane wing structural concept from the aeroelastic fixed wing MAV design, involving the use of a carbon-epoxy prepreg frame covered by a thin layer of latex, was adapted to create wings having size, weight and planform similar to that of a particular hummingbird example.

A mechanization concept was developed to create a biologically inspired vibratory flapping testbed that drives the wings at resonance and provides control over wingtip trajectories generated by the system. A feedback control circuit inspired by locust morphology was developed and implemented that automatically tunes the actuator drive signal to the resonant flapping frequency of the flexible wing structure. The circuit relies upon a strain-rate feedback signal from a thin film pvdf sensor applied to the wing surface. A simple means of varying the actuator signals to generate wingbeat patterns that approximately matched those exhibited by hummingbirds in hover, cruise, and reverse flight was also developed and implemented.

Today's fixed-wing MAVs have already demonstrated their potential to function as rapidly deployable autonomous aerial reconnaissance platforms. Such vehicles were infeasible only a decade ago, and virtually unthinkable another decade prior to that. Perhaps fifteen years hence, the currently infeasible hummingbird-like MAV concept will enjoy a similar liberation. An extremely agile ornithoptic MAV design would challenge the current state-of-the-art in control for vehicles with highly transient flight characteristics. Developing methods required to model and control a highly agile flapping MAV will promote the understanding of unsteady and nonlinear dynamic phenomena in general, and could have broader application to full-scale aircraft technology.

\section{REFERENCES}

1. Dalton, Stephen: The Miracle of Flight, Firefly Books, Willowdale, Ontario, 1999

2. McGowan, Anna-Maria R., Washburn, Anthony E., Horta, Lucas G., Bryant, Robert G., Cox, David E., Siochi, Emilie, J., Padula, Sharon L., Holloway, Nancy M., "Recent Results from NASA's Morphing Project," Proceedings of the SPIE 9th Annual International Symposium on Smart Structures and Materials, San Diego, California, March 17-21, 2002.

3. McGowan, Anna-Maria R. (ed.), "AVST Morphing Project Research Summaries in Fiscal Year 2001," NASA TM 2002211769, August 2002.

4. McGowan, A.R., Cox, D.E., Lazos, B.S., Waszak, M.R., Raney, D.L., Siochi, E.J., and Pao, S.P., Biologically inspired Technologies in NASA's Morphing Project. SPI Paper No. 5051-1 (Invited). Proceeding of the SPIE $10^{\text {th }}$ Annual International Symposium on Smart Structures and Materials, Electroactive Polymer Actuators and Devices Conference. San Diego, CA, March 2003.

5. Waszak, M.R., Jenkins, L.N., and Ifju, P., Stability and Control Properties of an Aeroelastic Fixed Wing Micro Aerial Vehicle. AIAA Paper 2001-4005, AIAA Atmospheric Flight Mechanics Conference, Montreal, Canada. Aug. 6-9, 2001. 
6. Waszak, M.R., Davidson, J.B., and Ifju, P.G., Simulation and Flight Control of an Aeroelastic Fixed Wing Micro Aerial Vehicle. AIAA Paper 2002-4875, AIAA Atmospheric Flight Mechanics Conference, Monterey, CA, Aug. 2002.

7. Ifju, P.G., Jenkins, D.A., Ettinger, S.J., Lian, Y., Shyy, W., and Waszak, M.R., Flexible-Wing-Based Micro Air Vehicles. AIAA Paper 2002-0705, AIAA Aerospace Sciences Meeting, Reno, NV, Jan. 2002.

8. Ifju, P.G., Ettinger, S., Jenkins, D.A., and Martinez, L., "Composite Materials for Micro Air Vehicles," Society for the Advancement of Materials and Process Engineering Annual Conference, Long Beach, CA, May 6-10, 2001.

9. Ettinger, S.M., Nechyba, M.C, Ifju, P.G., and Waszak, M.R., Towards Flight Autonomy: Vision-Based Horizon Detection for Micro Air Vehicles. IEEE/RSJ International Conf. on Intelligent Robots and Systems, EPFL, Switzerland, 2002.

10. Sellers, W. L., III and Kjelgaard, S. O., "The Basic Aerodynamics Research Tunnel - A Facility Dedicated to Code Validation," AIAA-88-1997, May, 1988.

11. Fleming, G.A., Bartram, S.M., Waszak, M.R., and Jenkins, L.N., Projection Moiré Interferometry Measurements of Micro Aerial Vehicle Wings. SPIE Paper 4448-16, SPIE Conference on Optical Diagnostics for Fluids, Solids, and Combustion, San Diego, CA, Jul. 29 - Aug. 3, 2001.

12. Liu, T., Graves, S.S., Ross, R. W., Eom, K.B., Hereford, J.M., "Computer Vision as a Universal Framework for Image-Based Measurements in Aerospace Engineering and Sciences." Final Report for FY2000 ISE Project, NASA Langley Research Center, Sept. 2000.

13. Grasmeyer, J.M. and Keennon, M.T., "Development of the Black Widow Micro Air Vehicle." AIAA Paper 2001-0127, Aerospace Sciences Meeting, Reno, NV, Jan. 2000.

14. Torres, G.E. and Mueller, T.J., "Aerodynamic Characteristics of Low Aspect Ratio Wings at Low Reynolds Numbers," Proceedings of Conference on Fixed, Flapping and Rotary Vehicles at Very Low Reynolds Numbers, ed. Thomas J. Mueller, University of Notre Dame, June 5-7, 2000, pp.278-305.

15. Anon., Using Simulink: Version 2. The Math Works, Inc. Natick, MA, Jan. 1997.

16. Bacon B.J., Ostroff A.J.: Reconfigurable Flight Control using Nonlinear Dynamic Inversion with a Special Accelerometer Implementation, AIAA 2000-4565, AIAA Guidance, Navigation and Control Conf., Denver, CO, Aug. 2000.

17. Anderson, M.R. and Robbins, A.C., "Formation Flight as a Cooperative Game," AIAA Paper 98-4124, AIAA Guidance, Navigation, and Control Conf., Boston, MA, Aug. 1998.

18. Lluch, D., Building Multi-UAV Simulation Methods. AIAA Paper 2002-4977, AIAA Modeling and Simulation Technologies Conference, Monterey, CA, Aug. 2002.

19. Dudley R., 2000: The Biomechanics of Insect Flight. Princeton Univ. Press, Princeton, NJ; ISBN 0-691-04430-9.

20. Dickinson M., 2001: Solving the Mystery of Insect Flight. Scientific American, Issue 601, June 2001.

21. Patil, Mayuresh J.: From Fluttering Wings to Flapping Flight: The Energy Connection, AIAA 2001-1460, 42 ${ }^{\text {nd }}$ AIAA/ASME Structures, Dynamics and Materials Conf., 16-19 April, 2001, Seattle, WA.
22. Yan J., Wood R. Avandhanula S., Sitti M., Fearing R.: Towards Flapping Wing Control for a Micro-mechanical Flying Insect. IEEE Robotics and Automation Conference, 2001.

23. Zbikowski R., Pedersen C.B., Hammed A., Friend C.M., Barton, C.P.: Current Research on Flapping Wing Micro Air Vehicles at Shrivenham. AVT Symposium on Unmanned Vehicles for Aerial Ground and Military Operations, Ankara, Turkey, Oct 2000.

24. Boisard T.M., 1998: Preliminary Design Considerations for Micro Air Vehicles: An Approach Based on Hummingbird Flight Characteristics. MS thesis presented to University of Texas at Austin, Dec 1998.

25. Shyy W., Berg M., Ljungqvist D., 1999: Flapping and Flexible Wings for Biological and Micro Vehicles. Progess in Aerospace Sciences, v.35, no.5, pp.455-506.

26. Mueller T. J. (editor): Conference on Fixed, Flapping and Rotary Wing Vehicles at Low Reynolds Numbers. Notre Dame University, Indiana, 5-7 June 2000.

27. Pornsin-Sisirak T., Lee S.W., Nassef H., Grasmeyer J., Tai Y.C., Ho C.M., Keenon M.: MEMS Wing Technology for a Battery-Powered Ornithopter. $13^{\text {th }}$ IEEE International Conference on Micro Electro Mechanical Systems, Miyazaki, Japan, 23-27 Jan 2000.

28. Frampton K.D., Goldfarb M.: Passive Aeroelastic Tailoring for Optimal Flapping Wings. Conference on Fixed, Flapping and Rotary Winged Vehicles for Very Low Reynolds Numbers, Notre Dame, IN, June 2000.

29. Dickinson M. H., Lehmann F., Sane S. P.: Wing Rotation and the Aerodynamic Basis of Insect Flight. Science, June 1999, v.284, pp.1954-1960.

30. Schenato L., Deng X., Sastry S.S.: Flight Control System for a Micromechanical Flying Insect: Architecture and Implementation. IEEE International Conference on Robotics and Automation, 2001.

31. Spedding G.R., Lissaman P.B.S., 1998: Technical Aspects of Microscale Flight Systems, J. Avian Biology, v.29, pp 458-468.

32. Greenwalt C.H., 1960: Hummingbirds. Doubleday \& Co., Garden City; ISBN 0-486-26431-9.

33. Chai P., Millard D., 1997: Flight and Size Constraints: Hovering Performance of Large Hummingbirds Under Maximal Loading. J. Experimental Biology, 1997, v.200, pp.921-929.

34. Ennos A.R., 1988: The Importance of Torsion in the Design of Insect Wings, J. Experimental Biology, v.140, pp.137-160.

35. Cummins J.: Notes on Avian Anatomy webpage, April 11996 , resketched from Freethy R., 1982: How Birds Work, A Guide to Bird Biology. 1st ed. Poole: Blanford Press. (http://numbat.murdoch.edu.au/Anatomy/avian/shoulderl.GIF)

36. Lasek M., Pietrucha J., Zlocka M., Sibilski K.: Analogies Between Rotary and Flapping Wings from Control Theory Point of View. AIAA-2001-4002, AIAA Atmospheric Flight Mechanics Conf, 6-9 August 2001, Montreal, Canada.

37. Raney D.L., Slominski E.C.: "Mechanization and Control Concepts for Biologically Inspired Micro Aerial Vehicles," AIAA Paper 2003-5345, AIAA Guidance, Navigation and Control Conference, Austin, TX, Aug. 2003.

38. Ennos A.R., 1988: The Inertial Cause of Wing Rotation in Diptera. J. Experimental Biology, v.140, pp.161-169. 